\title{
The impact of frozen sections on final surgical margins in squamous cell carcinoma of the oral cavity and lips: A retrospective analysis over an 11 years period
}

\author{
Stefan Gerber ${ }^{1 *}$, Carole Gengler ${ }^{2}$, Klaus W Grätz ${ }^{1}$ and Astrid L Kruse ${ }^{1}$
}

\begin{abstract}
Background: Taking intraoperative frozen sections (FS) is a widely used procedure in oncologic surgery. However so far no evidence of an association of FS analysis and premalignant changes in the surgical margin exists. Therefore, the aim of this study was to evaluate the impact of FS on different categories of the final margins of squamous cell carcinoma (SCC) of the oral cavity and lips.

Methods: FS, pT-stage, grading, and tumor localization of 178 patients with SCC of the oral cavity and lips were compared by uni- and multivariate analysis in patients with positive, dysplastic and negative surgical margin status. Results: Performed on 111 patients (62.4\%), intraoperative FS did not have any statistically significant influence on final margin status, independent of whether it was positive $(p=0.40)$, dysplastic $(p=0.70)$, or negative $(p=0.70)$. Positive surgical margins in permanent sections were significantly associated with pT4-tumors (OR 5.61, $p=0.001$ ). The chance for negative margins in permanent sections was significantly higher in tumors located in the tongue (OR 4.70, $\mathrm{p}=0.01$ ).
\end{abstract}

Conclusions: Our data suggests that intraoperative FS in SCC can be useful in selected cases. However it is not advisable as a routine approach.

Keywords: frozen section, surgical margin, squamous cell carcinoma, oral cavity, lips

\section{Background}

Although no consensus exists about what constitutes a "positive" surgical margin, it is widely accepted that tumors at the inked resection margin are associated with lower survival rates [1-5]. Therefore the surgeon's primary aim is to achieve a clear surgical margin and most, but not all [6,7], centers follow this practice.

Frozen section (FS) analysis costs USD $\$ 3,123$ on average per patient with an estimated cost-benefit ratio of 20:1[8]. Therefore, and because of increasing costs in the healthcare system, the diagnostic value of FS in head and neck oncological surgery was investigated recently. The impact of FS on survival and local recurrence is

\footnotetext{
* Correspondence: gerber.stefan@hotmail.com

'Department of Craniomaxillofacial and Oral Surgery, University Hospital

Zurich, (Frauenklinkstrasse 24), Zurich, (CH-8091), Switzerland Full list of author information is available at the end of the article
}

still controversial $[9,10]$. However, two studies including the same patient population $[5,11]$ showed no effect of FS on involved surgical margins, and Ribeiro et al. stated no effect on close surgical margins [12]. So far there is no evidence of an association of FS analysis with premalignant changes in the surgical margin of permanent slides.

The aim of this study was to investigate whether FS had any effect on different categories of the final surgical margins, including carcinoma in situ/dysplasia in the margin of oral/lip squamous cell carcinoma (SCC).

\section{Methods}

\section{Selection of surgical cases}

Between 1998 and 2008, 374 patients with head and neck cancer were treated at the Department of Craniomaxillofacial and Oral Surgery at the University Hospital
Ciomed Central 
of Zurich, Switzerland. Inclusion criteria for the study were as follows: (i) patient had SCC of the oral cavity or upper/lower lips; (ii) no previous surgical excision had been performed for this tumor; and (iii) the operation was done with curative intent. Overall 196 patients had to be excluded with 63 patients showing another tumor type. Other reasons for exclusion were other localization of the tumor, palliative surgery, patient already surgically treated before, missing charts with detailed clinical and pathological information and if only dysplasia was seen in permanent histological sections when initially a SCC was anticipated. Finally, 178 patients were included in the retrospective analysis.

The study design fulfills the criteria of paragraphs $4 \mathrm{a}$ and $b$ according to the guidelines of the cantonal ethics committee of Zurich and therefore is exempted from institutional review board approval.

\section{Data collection and definitions}

Clinical variables evaluated included gender, age, tumor localization, and surgical procedure, including neck dissection. The pathological variables examined comprised pT-stage, histologic grading 1-3, histologic subtype of SCC. If FS were performed, any area that was regarded as suspicious by the surgeon was sampled. The frozen and permanent sections were evaluated by different experienced pathologists. Further, we divided the histopathological margins of permanent sections into three categories:

1) Positive margins: Involved by invasive carcinoma (incl. perineural invasion within the margin).

2) Dysplastic margins: Involved by carcinoma in situ and/or low to high grade dysplasia without invasive carcinoma in the margin.

3) Negative margins: No involvement by invasive carcinoma, carcinoma in situ, or dysplasia.

In cases with dysplastic or negative margins, the minimal distance from tumor to resection margin was recorded and divided into three categories (i) $<1 \mathrm{~mm}$; (ii) $1-5 \mathrm{~mm}$; and (iii) $>5 \mathrm{~mm}$. All cases with positive or dysplastic margins in the permanent histological slides were examined to see if the FS showed infiltration with carcinoma (positive FS), dysplasia and/or carcinoma in situ (dysplastic FS), or if they were clear of any pathological changes (negative FS). Furthermore, it was noted if FS were performed on the same area where the histopathological changes in the permanent slide were seen.

\section{Data management and statistical analysis}

Data were analyzed with the SPSS 17.0 using chisquared tests for binary variables. As a baseline for regression analyses, variables were chosen on the basis of most data observed (pT1 for $\mathrm{pT}$-stage, lower jaw for tumor localization, and local resection for operations) or on the basis of pathological parameters (G1 for grading). Results of the statistical analysis with p-values smaller than $5 \%$ were considered to be statistically significant. Values bigger than $5 \%$, but smaller than $10 \%$, were interpreted as tendencies.

\section{Results}

A total of 178 patients (102 males and 76 females) were reviewed in this retrospective analysis. The mean age was 63.5 years (range 32 to 89 ). The site distribution is summarized in Table 1, with the lower jaw being the most common site encountered in 47 patients (26.4\%).

Tumor staging was as follows: pT1 in 83 (46.6\%), pT2 in $53(29.8 \%)$, pT3 in 10 (5.6\%), and pT4 in $32(18 \%)$ patients. Twenty-eight patients were identified with grade 1 histology (15.7\%), 108 with grade $2(60.7 \%)$ and 42 with grade 3 (23.6\%).

\section{Frozen sections}

FS to assess surgical margin status were performed on 111 of 178 patients $(62.4 \%)$ (Table 1).

In the group of patients where FS was performed, the final surgical margin was positive in 22 cases (19.8\%), being not significantly lower than in the pool of patients without FS (19 positive final margins of 67 cases without FS) $(28.4 \%$, OR 0.70, p = 0.40).

Dysplastic changes on final margins occurred more often when FS analysis was undertaken (12.6\% vs. $7.5 \%$, OR $1.26, \mathrm{p}=0.70)$. In our multivariate logistic regression analysis, the practice of using FS for achieving negative margins was not significantly associated with the margin status on permanent histological slides, independent of whether this was positive $(\mathrm{p}=0.40)$, dysplastic $(p=0.70)$, or negative $(p=0.70)$ (Table 2$)$. Univariate analysis confirmed these results.

The proportion of FS performed ranges from 15 of 32 cases $(46.9 \%)$ in pT4- tumors to 8 of 10 cases $(80 \%)$ in pT3-tumors and a multivariate logistic regression analysis confirmed that FS were significantly more often taken from pT2-tumors (OR 2.53, p = 0.03) compared to pT1-tumors. Tumor localization did not seem to have any statistically significant influence on the decision to take FS.

To focus on tumors with positive or dysplastic final surgical margins, FS were more frequently performed in cases with dysplastic than with positive margins (53.7\% vs. $73.7 \%)$. In the group of tumors with final positive surgical margins, FS analysis was undertaken in 22 of 41 cases (53.7\%), of which ten (45.5\%) showed invasive carcinoma or dysplasia in FS. In one half of these 10 cases, further FS were taken from the same site until a negative intraoperative result was obtained. In the other half, no further FS were taken, and the tumor was excised 


\begin{tabular}{|c|c|c|}
\hline & No. of cases & $\overline{\%}$ \\
\hline \multicolumn{3}{|l|}{ Patients } \\
\hline Men & 102 & $(57.3)$ \\
\hline Women & 76 & $(42.7)$ \\
\hline Mean age & 63.5 years & (range 32-89) \\
\hline \multicolumn{3}{|l|}{ Tumor localization } \\
\hline Lower jaw & 47 & (26.4) \\
\hline Tongue & 39 & (21.9) \\
\hline Floor of mouth & 34 & $(19.1)$ \\
\hline Upper jaw & 29 & (16.3) \\
\hline Upper and lower lips & 15 & (8.4) \\
\hline Other locations & 14 & (7.9) \\
\hline \multicolumn{3}{|l|}{ pT-Stage } \\
\hline pT1 & 83 & $(46.6)$ \\
\hline pT2 & 53 & $(29.8)$ \\
\hline pT3 & 10 & (5.6) \\
\hline pT4 & 32 & $(18.0)$ \\
\hline \multicolumn{3}{|l|}{ Grading } \\
\hline G1 & 28 & $(15.7)$ \\
\hline G2 & 108 & $(60.7)$ \\
\hline G3 & 42 & (23.6) \\
\hline \multicolumn{3}{|l|}{ Special features of tumors } \\
\hline Necrotic & 1 & (0.6) \\
\hline Ulceration & 30 & $(16.9)$ \\
\hline Bone invasion & 23 & (12.9) \\
\hline \multicolumn{3}{|l|}{ Surgical procedures* } \\
\hline Local resection & 68 & $(38.2)$ \\
\hline Lower jaw resection & 47 & (26.4) \\
\hline Floor of mouth/Tongue resection & 34 & $(19.1)$ \\
\hline Hemimaxillectomy/Upper jaw alveolar resection & 27 & $(15.2)$ \\
\hline Lips and other resections & 8 & (4.5) \\
\hline \multicolumn{3}{|l|}{ Final surgical margin status } \\
\hline Positive margin (involved by carcinoma) & 41 & (23.0) \\
\hline Dysplastic margin & 19 & $(10.7)$ \\
\hline - Carcinoma in situ & 1 & (0.5) \\
\hline - low/middle grade dysplasia & 9 & (5.1) \\
\hline - high grade dysplasia & 9 & (5.1) \\
\hline Negative margin & 118 & $(66.3)$ \\
\hline Distance carcinoma - resection margin & 137 & $(77.0)$ \\
\hline$-<1 \mathrm{~mm}$ & 27 & $(15.2)$ \\
\hline$-1-5 \mathrm{~mm}$ & 86 & (48.3) \\
\hline$->5 \mathrm{~mm}$ & 24 & (13.5) \\
\hline \multicolumn{3}{|l|}{ Frozen sections } \\
\hline Frozen sections done & 111 & (62.4) \\
\hline - in cases with positive final margin $(n=41)$ & 22 & (53.7) \\
\hline - in cases with dysplastic final margin $(n=19)$ & 14 & (73.7) \\
\hline - in cases with negative final margin $(n=118)$ & 75 & (63.6) \\
\hline
\end{tabular}

* More than one surgical procedure possible

with a wide margin at this crucial site. In all of the 10 cases with positive or dysplastic FS and final positive surgical margins, the sites from which FS were taken and the areas where the final surgical margin was positive were not identical. In 5 of the other 12 patients, FS were performed on the same site where the final 
Table 2 Multivariate logistic regression analysis of surgical margin status in permanent sections of oral and lip squamous cell carcinoma

\begin{tabular}{|c|c|c|c|c|c|c|c|c|c|c|c|c|}
\hline & \multicolumn{4}{|c|}{ Positive surgical margin $(n=41)$} & \multicolumn{4}{|c|}{ Dysplastic surgical margin $(n=19)$} & \multicolumn{4}{|c|}{ Negative surgical margin $(n=118)$} \\
\hline & No. of cases & Odds Ratio & $95 \% \mathrm{Cl}$ & $p$ Value & No. of cases & Odds Ratio & $95 \% \mathrm{Cl}$ & $p$ Value & No. of cases & Odds Ratio & $95 \% \mathrm{Cl}$ & $p$ Value \\
\hline Frozen sections done & 22 & 0.70 & $0.31-1.61$ & 0.40 & 14 & 1.26 & $0.39-4.07$ & 0.70 & 75 & 1.15 & $0.56-2.37$ & 0.70 \\
\hline \multicolumn{13}{|l|}{ pT-Stage } \\
\hline $\mathrm{pT}^{*}$ & 10 & - & - & - & 9 & - & - & - & 64 & - & - & - \\
\hline pT2 & 10 & 1.72 & $0.61-4.83$ & 0,31 & 9 & 1.39 & $0.47-4.09$ & 0.55 & 34 & 0.57 & $0.25-1.29$ & 0.18 \\
\hline рT3 & 4 & 4.44 & $0.97-20.35$ & 0.055 & 1 & 0.77 & $0.08-7.76$ & 0.83 & 5 & 0.33 & $0.08-1.38$ & 0.13 \\
\hline pT4 & 17 & 5.61 & $1.98-15.87$ & 0.001 & 0 & - & - & - & 15 & 0.42 & $0.16-1-07$ & 0.07 \\
\hline \multicolumn{13}{|l|}{ Grading } \\
\hline $\mathrm{G} 1^{*}$ & 5 & - & - & - & 2 & - & - & - & 21 & - & - & - \\
\hline $\mathrm{G} 2$ & 27 & 1.43 & $0.41-4.91$ & 0.57 & 12 & 1.35 & $0.26-7.07$ & 0.72 & 69 & 0.76 & $0.27-2.14$ & 0.61 \\
\hline G3 & 9 & 1.03 & $0.25-4.23$ & 0.97 & 5 & 1.21 & $0.19-7.68$ & 0.84 & 28 & 1.02 & $0.32-3.32$ & 0.97 \\
\hline \multicolumn{13}{|l|}{ Tumor localization } \\
\hline Lower jaw* & 19 & - & - & - & 5 & - & - & - & 23 & - & - & - \\
\hline Floor of mouth & 7 & 0.49 & $0.16-1.47$ & 0.20 & 7 & 1.44 & $0.37-5.57$ & 0.59 & 20 & 1.35 & $0.53-3.47$ & 0.53 \\
\hline Tongue & 3 & 0.21 & $0.05-0.84$ & 0.03 & 3 & 0.39 & $0.08-1.83$ & 0.23 & 33 & 4.70 & $1.55-14.23$ & 0.01 \\
\hline Upper and lower lips & 2 & 0.42 & $0.08-2.30$ & 0.32 & 1 & 0.38 & $0.04-3.70$ & 0.40 & 12 & 3.07 & $0.72-13.11$ & 0.14 \\
\hline Upper jaw & 8 & 0.77 & $0.25-2.35$ & 0.64 & 1 & 0.20 & $0.02-1.88$ & 0.16 & 20 & 2.09 & $0.75-5.85$ & 0.16 \\
\hline Other locations & 2 & 0.57 & $0.10-3.14$ & 0.52 & 2 & 0.73 & $0.12-4.52$ & 0.73 & 10 & 1.80 & $0.46-7.06$ & 0.40 \\
\hline
\end{tabular}


surgical margin was positive, which accounts for $22.7 \%$ of all patients with positive final surgical margin and positive, dysplastic or negative FS.

In 14 out of 19 patients (73.7\%) with dysplastic final surgical margin status, FS were performed. Half of these 14 patients showed positive or dysplastic FS; in one patient, the FS was repeated until a negative result was achieved; and in the other 6 cases, tumors were excised with a wider margin, without a second FS analysis undertaken. However, in 5 of these 6 tumors, dysplastic final surgical margins were reported as being located at the same site as the FS. In 11 of 14 patients (76.8\%), FS were located at the same site where the final surgical margin showed dysplasia/carcinoma in situ. Overall, in 16 out of 36 patients (44.4\%) with FS and positive or dysplastic final margins, the location was identical according to the pathology report.

\section{Final Surgical margin status}

In 41 of 178 patients (23\%), the histological margins of the permanent slides were involved with invasive carcinoma and were considered to be positive. Nineteen patients (10.7\%) showed either low/middle grade dysplasia (9 patients) or high grade dysplasia/carcinoma in situ (10 patients) in the final surgical margin and were considered to have dysplastic margins for data analysis. However, the majority of patients had negative surgical margins (118 patients, 66.3\%) (Table 1 ).
The chance of a positive final surgical margin is significantly increased by the factor 5 in pT4-stage tumors compared to pT1-tumors (OR 5.61, p =0,001). Showing the same tendency are pT3-stage tumors (OR 4.44, p = 0,055) (Table 2). Consequently, histologically proven bone invasion, which was reported in 23 of 178 cases (12.9\%), showed a significant correlation to positive surgical margins in permanent slides (OR 4.47, $\mathrm{p}<0.001$ ). Figure 1 demonstrates the increasing ratio of positive final margins with increasing $\mathrm{pT}$-stage, and the inverse correlation with negative surgical margins. Regarding the tumor site, the tongue is rarely associated with positive surgical margins in permanent slides (OR 0.21, p =0,03); consequently, tumors located at this site have a 4.7-fold increased chance of a negative surgical margin (OR 4.70, $\mathrm{p}=0.01$ ) (Table 2). This could be confirmed in a univariate logistic regression analysis demonstrating significantly more frequent negative final surgical margins after floor-of-mouth resection, including tongue resection, compared to local resection (OR 4.19, $\mathrm{p}=0.01$ ). In addition, floor of mouth and tongue resection (OR 0.17, $\mathrm{p}=0.09$ ) and hemimaxillectomy including upper alveolar resection (OR 0.14, $\mathrm{p}=0.06$ ) both tend to be associated with dysplastic final surgical margins in permanent slides (Table 3 ).

\section{Distance from tumor to resection margin}

Out of 137 surgical specimens with dysplastic or negative margin status in permanent slides, 110 tumors

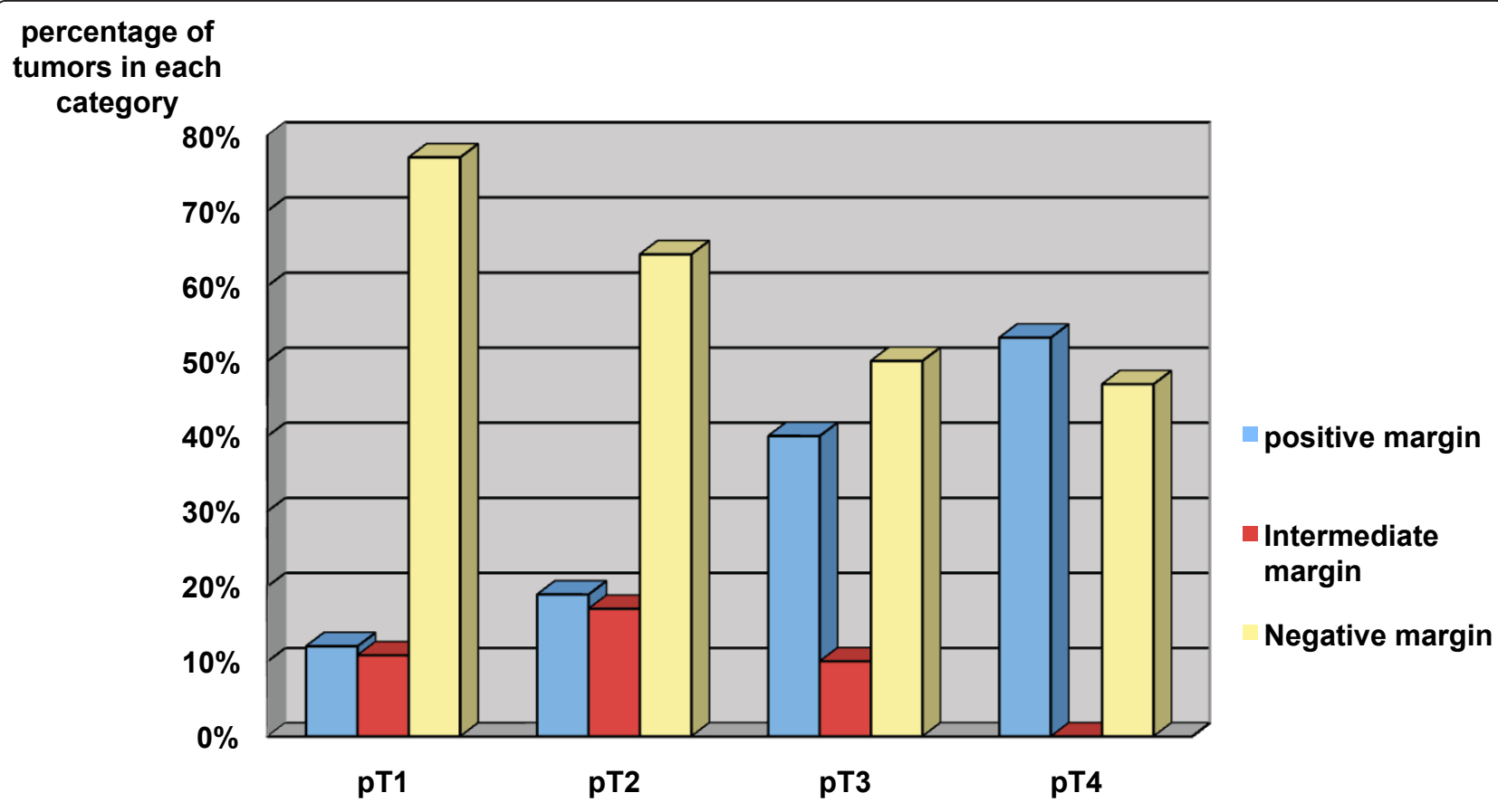

pT-stage

Figure 1 Margin status in relation to pT-stage. 
Table 3 Univariate logistic regression analysis about different surgical procedures and the surgical margin status

\begin{tabular}{|c|c|c|c|c|c|c|c|c|c|c|c|c|}
\hline & \multicolumn{4}{|c|}{ Positive surgical margin $(n=41)$} & \multicolumn{4}{|c|}{$\begin{array}{l}\text { Dysplastic surgical margin }(\mathrm{n}= \\
\text { 19) }\end{array}$} & \multicolumn{4}{|c|}{$\begin{array}{l}\text { Negative surgical margin }(n= \\
118)\end{array}$} \\
\hline & $\begin{array}{l}\text { No. of } \\
\text { cases }\end{array}$ & $\begin{array}{l}\text { Odds } \\
\text { Ratio }\end{array}$ & $\begin{array}{c}95 \% \\
\mathrm{Cl}\end{array}$ & $\begin{array}{c}p \\
\text { Value }\end{array}$ & $\begin{array}{l}\text { No. of } \\
\text { cases }\end{array}$ & $\begin{array}{l}\text { Odds } \\
\text { Ratio }\end{array}$ & $\begin{array}{c}95 \% \\
\mathrm{Cl}\end{array}$ & $\begin{array}{c}p \\
\text { Value }\end{array}$ & $\begin{array}{l}\text { No. of } \\
\text { cases }\end{array}$ & $\begin{array}{l}\text { Odds } \\
\text { Ratio }\end{array}$ & $95 \% \mathrm{Cl}$ & $\begin{array}{c}\mathrm{p} \\
\text { Value }\end{array}$ \\
\hline \multicolumn{13}{|l|}{ Operations } \\
\hline Local resection* & 16 & - & - & - & 14 & - & - & - & 38 & - & - & - \\
\hline $\begin{array}{l}\text { Hemimaxillectomy/Upper jaw } \\
\text { alveolar resection }\end{array}$ & 6 & 0.93 & $\begin{array}{l}0.33- \\
2.74\end{array}$ & 0.93 & 1 & 0.17 & $\begin{array}{c}0.02- \\
1.33\end{array}$ & 0.09 & 20 & 2.03 & $\begin{array}{l}0.77- \\
5.37\end{array}$ & 0.15 \\
\hline $\begin{array}{l}\text { Floor of mouth/Tongue } \\
\text { resection }\end{array}$ & 4 & 0.42 & $\begin{array}{c}0.13- \\
1.32\end{array}$ & 0.14 & 1 & 0.14 & $\begin{array}{l}0.02- \\
1.08\end{array}$ & 0.06 & 29 & 4.19 & $\begin{array}{l}1.48- \\
11.83\end{array}$ & 0.01 \\
\hline Lower jaw resection & 16 & 1.92 & $\begin{array}{c}0.87- \\
4.25\end{array}$ & 0.11 & 4 & 0.44 & $\begin{array}{l}0.14- \\
1.46\end{array}$ & 0.18 & 27 & 0.83 & $\begin{array}{l}0.40- \\
1.72\end{array}$ & 0.61 \\
\hline Other operations & 1 & 0.45 & $\begin{array}{l}0.05- \\
3.84\end{array}$ & 0.46 & 0 & - & - & - & 7 & 5.06 & $\begin{array}{l}0.60- \\
42.91\end{array}$ & 0.14 \\
\hline
\end{tabular}

* Baseline

* Basel

(80.3\%) were located at least $1 \mathrm{~mm}$ away from the surgical margin with a distance between 1 and $5 \mathrm{~mm}$ most often reported (in 86 of 137 cases, 62.8\%) (Table 1).

The distance from tumor to resection margin is significantly influenced by pT-stage $(\mathrm{pT} 2 \mathrm{p}=0.03, \mathrm{pT} 3 \mathrm{p}=$ 0.01 , pT4 p < 0.001) and by tumors located in the tongue $(\mathrm{p}=0.01)$. At this site, 22 of 39 tumors $(56.4 \%)$ were located within 1-5 mm from the final margin and only 3 surgical specimens (7.7\%) showed infiltration of the margin by invasive carcinoma. Figure 2 demonstrates the correlation of $\mathrm{pT}$-stage with distance from tumor to final resection margin. With increasing distance to surgical margin, the proportion of pT1-tumors increases from $24.4 \%$ with positive margins to $70.8 \%$ with a clear margin of more than $5 \mathrm{~mm}$. The inverse correlation is illustrated for pT4-tumors with a decrease from $41.5 \%$ to $4.2 \%$.

\section{Discussion}

All together 178 patients were studied, presenting with SCC of the oral cavity or lips between 1998 and 2008, who were surgically treated with a curative intention. In 111 (62.5\%) patients, intraoperative FS for margin evaluation were performed. The practice of taking FS did not have any statistically significant influence on the final margin status of the surgical specimen, irrespective of whether the margin was involved by invasive carcinoma or by dysplasia/carcinoma in situ. Furthermore, the data support that FS may be negative, although taken from the same area where the final surgical margin was classified as positive or dysplastic. However, final surgical margin status was significantly associated with two factors: tumor localization and pT-stage. Tumors located in the tongue led more often to negative margins, and pT4-tumors had 5 times as many positive margins as $\mathrm{pT} 1$-tumors. In negative or dysplastic final surgical margins, the distance from tumor to resection margin increased with $\mathrm{pT}$-stage and showed a significant correlation to tumors located in the tongue.

The influence of FS on final surgical margin status had not been assessed until lately. Binahmed et al. [5] examined the clinical significance of positive surgical margins in permanent slides in a cohort of 425 patients with oral SCC. The diagnosis was biopsy-proven, and patients had been previously untreated. Intraoperative FS, performed on $52.9 \%$ of the patients, were associated neither with involved nor with clear final margins. However, there are no p-values available in this paper, and it is not clear if uni- or multivariate analysis was used. Similar results were published by Nason et al. [11], who investigated the same patient cohort as Binahmed et al [5]. They performed a subgroup-analysis with a remaining cohort of 277 patients, recording the width of the clear margin. Like in both studies, we also could not find any significant association of FS and margin status, independent of whether the final margin was positive, dysplastic, or negative.

Byers et al. [13] reviewed 216 patients with SCC of the head and neck, who underwent surgical treatment including FS analysis. Of these tumors, 67\% were adequately excised through the surgeon's judgement. Moreover, in the current study, in 36 of 60 patients $(60 \%)$, positive or dysplastic final surgical margins went undetected in spite of using FS. In more recent studies this figure for undetected positive surgical margins ranges between $15.4 \%$ and $83.3 \%[8,10,12,14]$, raising the question about the diagnostic value of FS.

In only 16 of the 36 patients (44.4\%), FS were located in the same area where the final surgical margin showed pathological changes. This finding demonstrates one of the main limitations of FS: the sampling $[6,15]$. Tumors are 3-dimensional structures, and it is not practicable to evaluate the whole surgical margin by means of FS [1]. This highlights the importance of sampling the crucial 


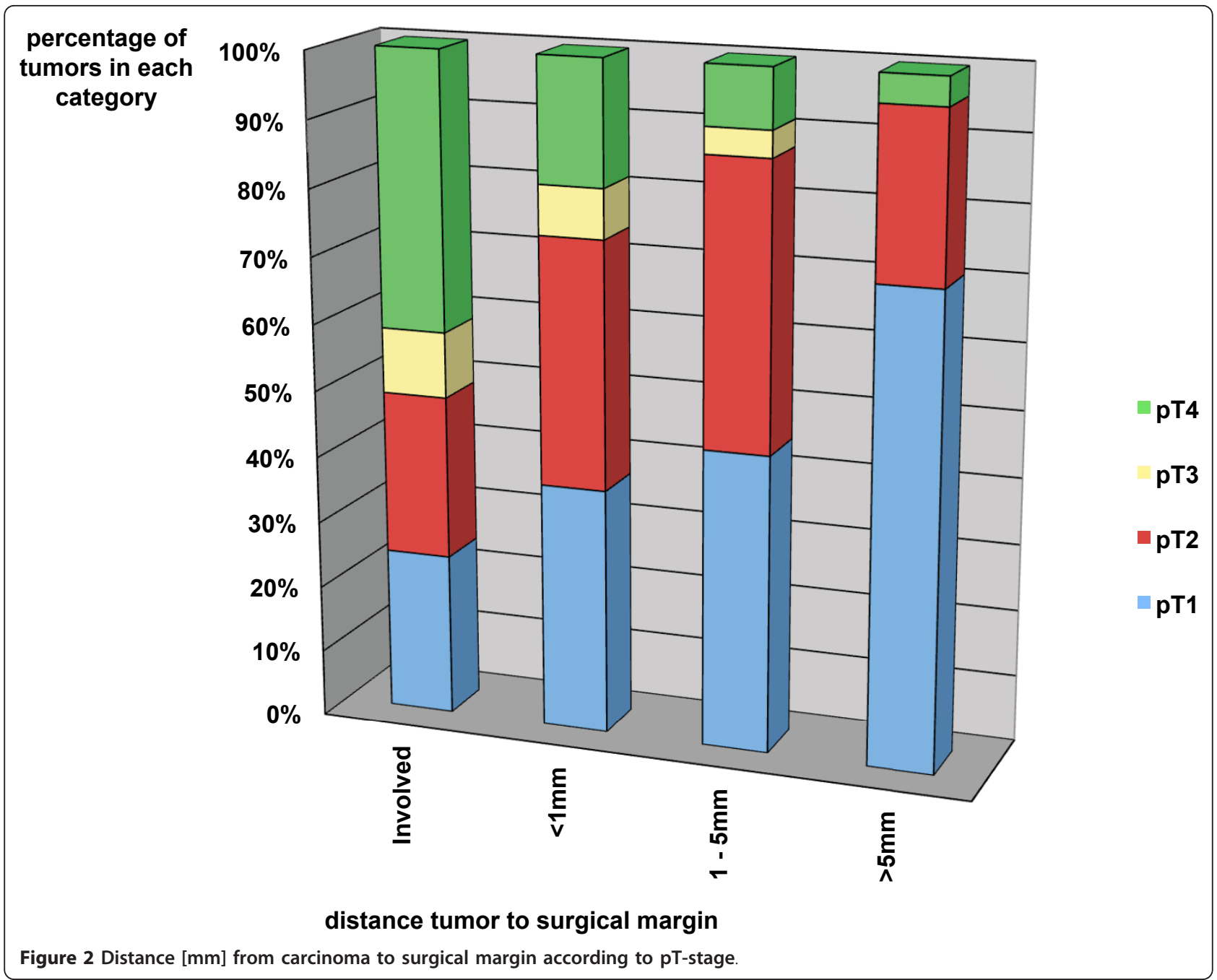

sites from which FS should be taken. So far no reliable test exists to detect in-vivo where the tumor front is located.

After an initially positive FS, a second FS was done in 3 of 17 patients $(17.6 \%)$ until it was negative. In one of these 3 patients, dysplasia was found in the margin of the permanent section at the same site. The procedure of doing multiple FS at the same site leads to another source of bias: the relocation by the surgeon. Kerawala et al. [16] showed that the mean error in relocating the site of FS in oropharyngeal cancer is $9 \mathrm{~mm}$ for samples at the mucosal margin and $12 \mathrm{~mm}$ for samples placed deep into the tumor.

Meier, Oliver, and Varvares [7] found in their survey of 1500 members of the International American Head and Neck Society, that $97 \%$ use FS for margin evaluation in the oral cavity and pharynx, with $76 \%$ taking those from the surgical bed and 14\% from the resected surgical specimen. However, no explicit evidence exists on whether FS should be taken at the surgical bed or from the specimen $[7,14]$.

Positive surgical margins, one of the most important prognostic factors [17], are 1.7 times more likely to be encountered in oral carcinoma than in other head and neck tumors [1]. In the present study, $23 \%$ of all the patients had a positive final surgical margin in permanent sections. This finding is similar to the results of other studies that reported ratios between $4.5 \%$ and $52.9 \%[1-5,11,12,14,18,19]$.

Tumors from the tongue were associated more frequently with negative surgical margin status in our study, a fact that has been reported before [18]. This may be explained by the fact that the circumference of the tumor is easily palpable and that less anatomical limits give a good surgical access to the tumor site.

The present study has a number of limitations. It did not differentiate between patients with and without prior radiotherapy. Preoperative radiotherapy is often 
associated with extensive fibrosis and inflammatory reaction, which makes the surgical resection and the histopathological assessment of FS more difficult [20]

\section{Conclusion}

In conclusion, the present results show that the diagnostic value of intraoperative FS for margin assessment in SCC of the oral cavity and lips is limited. Even in cases with reported negative FS, the final surgical margin of immediately adjacent tissue can be positive in the final histological evaluation. This highlights the fact that FS are only as good as the sampling is [12], although the accuracy of FS itself was previously reported to be over $98 \%[8,12]$.

The practice of routinely doing FS in SCC of the oral cavity and the lips is questionable. It does not seem to significantly influence the outcome of final surgical margin status and in some situations it may even mislead the surgeon. The necessity of taking FS should be evaluated case by case. The specific situations in which FS are necessary and what is the most useful sampling protocol may be the subject of further studies.

\section{Author details \\ ${ }^{1}$ Department of Craniomaxillofacial and Oral Surgery, University Hospital Zurich, (Frauenklinkstrasse 24), Zurich, (CH-8091), Switzerland. ²Department of Pathology, University Hospital Zurich, (Schmelzbergstrasse 12,) Zurich, (CH- 8091), Switzerland.}

\section{Authors' contributions}

SG and AK conceived of the study, participated in its design and coordination. SG and AK drafted and designed the manuscript and contributed equally to this work. CG made substantial contribution to data acquisition and conception of manuscript. CG and KG were involved in revising the manuscript. All authors read and approved the final manuscript.

\section{Competing interests}

The authors declare that they have no competing interests.

Received: 29 November 2011 Accepted: 30 December 2011 Published: 30 December 2011

\section{References}

1. Jones AS, Bin Hanafi Z, Nadapalan V, Roland NJ, Kinsella A, Helliwell TR: Do positive resection margins after ablative surgery for head and neck cancer adversely affect prognosis? A study of 352 patients with recurrent carcinoma following radiotherapy treated by salvage surgery. Br J Cancer 1996, 74:128-132.

2. Machtay M, Perch S, Markiewicz D, Thaler E, Chalian A, Goldberg A, Kligerman M, Weinstein G: Combined surgery and postoperative radiotherapy for carcinoma of the base of radiotherapy for carcinoma of the base of tongue: analysis of treatment outcome and prognostic value of margin status. Head Neck 1997, 19:494-499.

3. Sutton DN, Brown JS, Rogers SN, Vaughan ED, Woolgar JA: The prognostic implications of the surgical margin in oral squamous cell carcinoma. Int J Oral Maxillofac Surg 2003, 32:30-34.

4. Kovacs AF: Relevance of positive margins in case of adjuvant therapy of oral cancer. Int J Oral Maxillofac Surg 2004, 33:447-453.

5. Binahmed A, Nason RW, Abdoh AA: The clinical significance of the positive surgical margin in oral cancer. Oral Oncol 2007, 43:780-784.

6. Woolgar JA: T2 carcinoma of the tongue: the histopathologist's perspective. Br J Oral Maxillofac Surg 1999, 37:187-193.
7. Meier JD, Oliver DA, Varvares MA: Surgical margin determination in head and neck oncology: current clinical practice. The results of an International American Head and Neck Society Member Survey. Head Neck 2005, 27:952-958.

8. DiNardo LJ, Lin J, Karageorge LS, Powers CN: Accuracy, utility, and cost of frozen section margins in head and neck cancer surgery. Laryngoscope 2000, 110:1773-1776

9. Scholl P, Byers RM, Batsakis JG, Wolf P, Santini H: Microscopic cut-through of cancer in the surgical treatment of squamous carcinoma of the tongue. Prognostic and therapeutic implications. Am J Surg 1986, 152:354-360

10. Pathak KA, Nason RW, Penner C, Viallet NR, Sutherland D, Kerr PD: Impact of use of frozen section assessment of operative margins on survival in oral cancer. Oral Surg Oral Med Oral Pathol Oral Radiol Endod 2009, 107:235-239.

11. Nason RW, Binahmed A, Pathak KA, Abdoh AA, Sandor GK: What is the adequate margin of surgical resection in oral cancer? Oral Surg Oral Med Oral Pathol Oral Radiol Endod 2009, 107:625-629.

12. Ribeiro NF, Godden DR, Wilson GE, Butterworth DM, Woodwards RT: Do frozen sections help achieve adequate surgical margins in the resection of oral carcinoma? Int J Oral Maxillofac Surg 2003, 32:152-158.

13. Byers RM, Bland Kl, Borlase B, Luna M: The prognostic and therapeutic value of frozen section determinations in the surgical treatment of squamous carcinoma of the head and neck. Am J Surg 1978, 136:525-528.

14. Yahalom R, Dobriyan A, Vered M, Talmi YP, Teicher S, Bedrin L: A prospective study of surgical margin status in oral squamous cell carcinoma: a preliminary report. J Surg Oncol 2008, 98:572-578.

15. Gandour-Edwards RF, Donald PJ, Wiese DA: Accuracy of intraoperative frozen section diagnosis in head and neck surgery: experience at a university medical center. Head Neck 1993, 15:33-38.

16. Kerawala CJ, Ong TK: Relocating the site of frozen sections-is there room for improvement? Head Neck 2001, 23:230-232.

17. Woolgar JA, Rogers SN, Lowe D, Brown JS, Vaughan ED: Cervical lymph node metastasis in oral cancer: the importance of even microscopic extracapsular spread. Oral Oncol 2003, 39:130-137.

18. Woolgar JA, Triantafyllou A: A histopathological appraisal of surgical margins in oral and oropharyngeal cancer resection specimens. Oral Oncol 2005, 41:1034-1043.

19. Patel RS, Goldstein DP, Guillemaud J, Bruch GA, Brown D, Gilbert RW, Gullane PJ, Higgins KM, Irish J, Enepekides DJ: Impact of positive frozen section microscopic tumor cut-through revised to negative on oral carcinoma control and survival rates. Head Neck 2010, 32:1444-1451.

20. Ord RA, Aisner S: Accuracy of frozen sections in assessing margins in oral cancer resection. J Oral Maxillofac Surg 1997, 55:663-669, discussion 669671.

doi:10.1186/1758-3284-3-56

Cite this article as: Gerber et al:: The impact of frozen sections on final surgical margins in squamous cell carcinoma of the oral cavity and lips: A retrospective analysis over an 11 years period. Head \& Neck Oncology 2011 3:56.

\section{Submit your next manuscript to BioMed Central and take full advantage of:}

- Convenient online submission

- Thorough peer review

- No space constraints or color figure charges

- Immediate publication on acceptance

- Inclusion in PubMed, CAS, Scopus and Google Scholar

- Research which is freely available for redistribution 